\title{
Occupational exposures to solvents and aluminium and estimated risk of Alzheimer's disease
}

\author{
Amy B Graves, Daniel Rosner, Diana Echeverria, James A Mortimer, Eric B Larson
}

Department of

Epidemiology and

Biostatistics,

University of South

Florida, Tampa, FL,

USA

A B Graves

J A Mortimer

Center for Health Studies, Group Health Cooperative of Puget

Sound, Seattle, WA,

USA

D Rosner

Battelle Centers for Public Health

Research, Seattle, WA,

USA

D Echeverria

Institute on Aging University of South Florida, Tampa, FL, USA

J A Mortimer

Department of Medicine, University of Washington, Seattle, WA, USA

E B Larson

Correspondence to: Dr Amy B Graves,

Department of Epidemiology and Biostatistics, College of Public Health, MDC-56,

University of South Florida, 13201 Bruce B Downs Boulevard, Tampa, FL 33612, USA.

Accepted 31 March 1998

\begin{abstract}
Objectives-To study the role of occupational exposures to solvents and aluminium in the aetiology of Alzheimer's disease (AD). An industrial hygienist rated exposure.

Methods-89 subjects diagnosed with probable AD were matched by age, sex, and type of informant to 89 controls. Subjects were identified from a large health maintenance organisation in Seattle, WA. A complete occupational history was obtained from spouses of cases and controls as well as from controls themselves. After the interview an industrial hygienist, blinded to case-control status, rated exposures.
\end{abstract}

Results-Non-significant associations were found between AD and ever having been occupationally exposed to solvents (odds ratio (OR) $1.77,95 \%$ confidence interval (95\% CI) 0.81 to 3.90 ) and aluminium (OR 1.46, 95\% CI 0.62 to 3.42 ). Although an increasing risk was found with increasing number of years of exposure to solvents, there was an inverse association between exposure intensity and AD, and measures of cumulative exposure taking into account both intensity and duration of exposure were not significant. Analysis of the age at which half the cumulative exposure to solvents was achieved showed that an older age incurred a greater risk of AD than a younger age. However, the total amount of exposure carried no risk.

Conclusions-The results suggest that lifetime occupational exposure to solvents and aluminium are not likely to be important risk factors for Alzheimer's disease. (Occup Environ Med 1998;55:627-633)

Keywords: Alzheimer's disease; solvents; aluminium

Although genes are known to play a critical part in the aetiology of Alzheimer's disease (AD), ${ }^{16}$ there is growing evidence to suggest that exposures in the environment may modify the age of onset and lifetime risk of the disease. ${ }^{710}$ Interest in the potential role of environmental neurotoxins in $\mathrm{AD}$ has been longstanding. Exposure to solvents is known to be neurotoxic. ${ }^{11}$ However, epidemiological studies have reported both positive ${ }^{12-14}$ and negative ${ }^{15-22}$ results. These studies were based on exposures occurring as a result of the subject's principal lifetime occupation. Only one study ${ }^{23}$ obtained lifetime occupational histories and used a panel of occupational hygienists to rate exposures; this study did not find an increased odds ratio (OR) for solvent exposure given a statistical power of $82 \%$. Aluminium is also neurotoxic, has been shown to produce neurofibrillary degeneration in animals, ${ }^{24} 25$ and has been found to aggregate in neurofibrillary tangles, ${ }^{26}$ but has not been found in neuritic plaquesthe other pathological hallmark of $\mathrm{AD} .^{27}$

In the present study, we individually matched 89 probable cases of $\mathrm{AD}$ to 89 controls and obtained lifetime job histories from case and control spouses and from the controls themselves. Additionally, an industrial hygienist rated exposures for each job reported by the spouses, blinded to case-control status. The cases and controls in this analysis are a subset of those from a larger study, ${ }^{12}$ in which a positive association was reported between solvent exposure as assessed from primary lifetime occupation and $\mathrm{AD}$. We limited case and control selection to subjects with spouses whom we thought could provide the most accurate job information, and obtained ORs for solvent and aluminium exposures from the industrial hygienist blinded exposure ratings. Past studies have primarily used informants' ratings of exposure; thus this study has the benefit of not being subject to recall bias.

\section{Materials and methods}

CASES

Since 1987, patients with newly diagnosed dementia have been enrolled in the University of Washington Alzheimer's disease patient registry (ADPR) ${ }^{28}$ This registry exists within a large health maintenance organisation in Seattle, WA (Group Health Cooperative). Methods for locating subjects for the patients'registry have been described elsewhere. ${ }^{28}{ }^{29}$ The criteria developed by the National Institute of Neurological and Communicative Disorders and Stroke and the Alzheimer's Disease and Related Disorders Association (NINCDS/ ADRDA) were used to diagnose AD. ${ }^{30}$ Of all registry patients enrolled, about $57 \%$ were given a clinical diagnosis of probable or possible $\mathrm{AD}, 15 \%$ were given another dementia diagnosis, and $28 \%$ were found not to be demented. ${ }^{12}$ The current study required that both cases and controls have spouse informants. Of 344 probable AD cases, 173 (50.3\%) had a spouse, and $130(75.1 \%)$ of these agreed to have their names referred to the current study and were invited to participate. 
CONTROLS

Controls were randomly drawn from the same Group Health Cooperative population ${ }^{29}$ and were considered ineligible for both the parent and the current studies if they had dementia or other neurological disease causing dementia. In the parent study, of 542 eligible controls frequency matched to cases by age and sex, 243 agreed to participate. ${ }^{16}$ Controls were required to obtain a score of 28 of 30 on the mini mental state examination ${ }^{31}$ (27 if they were aged $\geqslant 80$ ). Of 329 controls from the Alzheimer's disease patient register from the parent study, $204(62 \%)$ had spouses and $166(81 \%)$ agreed to be referred to the current study. One control was matched to each case by age ( 67 pairs \pm 2 years; 22 pairs \pm 5 years) and sex. All subjects gave written informed consent. The study was approved by the University of Washington, Group Health Cooperative and Battelle Human Subjects Committees.

\section{EXPOSURE ASSESSMENT}

A trained interviewer administered a structured in person questionnaire to the case spouse. Control spouses and controls were interviewed concomitantly by two interviewers. Cases were assigned a reference year, which was one year earlier than the age at which the earliest symptoms of memory dysfunction were reported by the Alzheimer's disease patient register informant. The same reference year was assigned to each matched control. The occupational history was assessed in two steps. Firstly, a life calendar was designed beginning in 1905 and ending in 1992. The subjects' life events were mapped on the life calendar, beginning with their residential history from the age of 16 (town, state, and country and number of years in each location), the year of their children's births, and the name of each child. Information obtained from the life calendar was used to help guide the informant in recalling full time and part time jobs held by the case or control for one year or longer since the age of 16 and the number of years of employment on each job. Data collected from the informant and the controls included the name of the company, what the company did or made, a description of what the subject did in each job held, and the job title.

After data collection, an industrial hygienist (DE) was given a list of all job information and, blinded to case-control status, rated each job for exposure to solvents and aluminium. The job histories used for these ratings were given by the case spouse (for cases) and by the control spouse (for controls). (The job histories given by the controls for themselves were also rated by the industrial hygienist.) Each job was assigned a rating of exposure intensity with 0 representing no exposure, and $1,2.5$, and 5 representing low, moderate, and high exposure, respectively. This is a common professional activity for industrial hygienists, who are trained to recognise and assess chemical exposures in the workplace. ${ }^{32-35}$ Other data used in these analyses include age, sex, and education ( $<11$ th grade; completed 12 th grade; $>12$ th grade), gathered in the interviews with the informants and with the controls; data used here were those collected from the informants.

The assignment of solvent exposure was based on the industrial hygienist's (DE) review of the work histories. Five classes of solvents were included in the assessment which were considered representative of typical solvent use in industry (with examples): (a) aromatic compounds (toluene and xylene), (b) chlorinated solvents (trichloroethylene and methylene chloride), (c) ketones (acetone), (d) fuels (gasoline and kerosene), and (e) alcohols (wood alcohol and ethanol).

\section{DATA ANALYSIS}

Unadjusted ORs for ever or never exposure were calculated ${ }^{36}$ based on the expert industrial hygienist's blinded assessment of whether the subject had ever been exposed to solvents and aluminium in any job based on the spouse's description of the job, the company, and the job title. Conditional logistic regression ${ }^{37}$ was used for estimation of $95 \%$ confidence intervals (95\% CIs) and multivariate modelling. Confidence intervals for the adjusted risk estimates were calculated from the log OR. $\chi^{2}$ Tests were also applied to assess the associations between covariates such as education and exposure. ${ }^{36}$

Four techniques were used to examine doseresponse relations. (1) Three categorical levels of exposure were created using the distribution of the number of exposed years among controls (as reported by the spouses with the life calendar method). People were assigned a code of 0 if they were reported as not exposed occupationally to solvents or aluminium. Low and high exposures were determined by whether the number of years exposed was less than or greater than the median number of exposure years among the controls, respectively. Dummy variables were used in the conditional logistic regression and a single linear parameter was run in a separate model to test for trend. (2) Conditional logistic regression models were run, with the intensity rating to test whether increasing maximum intensity of exposure (without regard to duration of exposure) was associated with increasing risk of AD. (3) To test the effect of duration of exposure, the industrial hygienist's intensity rating was multiplied by the number of years at each job, summed over all jobs and dichotomised at the median. (4) To examine exposure timing, the age at which each exposed person had accumulated half of their total lifetime exposure was calculated.

To assess whether the association between exposure and disease varied by a third variable (such as sex), interaction terms between the third variable and exposure were entered into the conditional logistic regression. All data were analysed with SAS. ${ }^{38}$

\section{Results}

Of 130 eligible cases and 166 controls referred from the parent study, 21 case spouses $(16 \%)$ and 49 control spouses $(29.5 \%)$ refused to participate in this study (table 1). Several spouses died before being interviewed and no suitable match could be found for six addi- 
Table 1 Participation status of 89 matched case-control triplets from initially eligible subjects

\begin{tabular}{|c|c|c|c|c|c|c|c|c|c|}
\hline & \multicolumn{3}{|c|}{ Case spouse } & \multicolumn{3}{|c|}{ Control spouse } & \multicolumn{3}{|c|}{ Control } \\
\hline & All & Men & Women & All & Men & Women & All & Men & Women \\
\hline Total number eligible & 130 & 56 & 74 & 166 & 68 & 98 & 166 & 68 & 98 \\
\hline Refused & 21 & 6 & 15 & 49 & 21 & 28 & 48 & 20 & 28 \\
\hline Died & 3 & 3 & 0 & 1 & 1 & 0 & 3 & 2 & 1 \\
\hline No suitable match & 6 & 5 & 1 & 21 & 9 & 12 & 21 & 10 & 11 \\
\hline Completed interviews & 99 & 41 & 58 & 95 & 36 & 59 & 94 & 37 & 57 \\
\hline Control match refused & 4 & 4 & 0 & 5 & 1 & 4 & 6 & 0 & 6 \\
\hline Successfully matched & 89 & 36 & 53 & 89 & 36 & 53 & 89 & 36 & 53 \\
\hline
\end{tabular}

tional cases and 21 controls. A total of 99 case spouse, 95 control spouse, and 94 control interviews were completed. There were additional cases for which the control match declined to participate, resulting in a total of 89 matched pairs and 86 matched triplets. Table 2 shows the characteristics of participants with completed interviews compared with refusals and those in the parent sample, which includes cases and controls with all types of proxy respondents. Compared with the larger earlier sample, participants in the current study were more likely to be male, younger, and more educated. Compared with refusers, participating cases were more likely to be female, younger, better educated, and white, and participating controls were more likely to be male and younger. Potential controls who refused and those who participated had similar education and ethnicity.

Table 3 shows the proportions of subjects reported by the industrial hygienist to have ever been exposed occupationally to solvents or aluminium. The mean number of jobs reported by spouses for cases and controls did not differ from one another (mean (SD) cases 4.2 (2.2); controls 4.4 (2.6), $\mathrm{p}=0.54)$; nor did the average duration of job (mean (SD) cases 8.8 (9.3), $\mathrm{n}=373$; controls 8.3 (8.9), $\mathrm{n}=393, \mathrm{p}=0.41$ ) or the total years worked during their careers (mean (SD) cases 37.0 (18.2), controls 36.6 (18.7), $\mathrm{p}=0.89)$. Controls themselves reported a mean (SD) of 5.5 (2.8) jobs, with a duration of 7.3 (8.2) years and a total of $39.7(17.1)$ years of work.

\section{SOLVENTS}

Twenty nine discordant pairs formed the crude OR for solvents. The adjusted OR for ever having been exposed to solvents was 1.77 and was not significant $(95 \%$ CI 0.8 to 3.9$)$. When duration of years of exposure alone was used as the measure of dose, there was a doubling of the OR which was significant $(p=0.03)$. Analysis of the intensity measure (model 3) showed an inverse (but not significant) trend to that expected, with lower intensity being associated with a greater risk of $\mathrm{AD}$. When intensity of exposure was multiplied by the number of years exposed (model 4 ), there was only a weak increase in the ORs with increasing dose, and the test for trend was not significant $(p=0.13$, table 4).

For the age at which half the cumulative exposure to solvents was achieved (model 5), the adjusted OR was 1.02 (95\% CI 1.0 to 1.04 ) for the continuous variable. We created dummy variables for this continuous measure, stratifying at the median age at half cumulative exposure among controls. Although younger age at half cumulative exposure was not predictive of $\mathrm{AD}$ (age $\leqslant 33$, OR $1.2,95 \%$ CI 0.5 to 3.0 ), older age predicted $\mathrm{AD}$ (age $>33, \mathrm{OR}=2.7$, $95 \%$ CI 1.0 to 6.9 ). However, the test for trend was not significant $(p=0.12)$. To test whether this effect was due merely to the timing of exposure or whether it was due to the amount of exposure, we reran this model adding a variable for the cumulative dose (intensity $\times$ duration) that an exposed person had received. The ORs for half cumulative exposure, adjusted for

Table 2 Characteristics of matched pair sample (completed interviews) compared with those of refusals and ADPR/GD十 sample

\begin{tabular}{|c|c|c|c|c|c|c|}
\hline & \multicolumn{2}{|c|}{ Matched pair sample } & \multicolumn{2}{|l|}{ Refusals } & \multicolumn{2}{|c|}{ ADPR/GD sample } \\
\hline & Cases (\%) & Controls (\%) & Cases (\%) & Controls (\%) & Cases (\%) & Controls (\%) \\
\hline \multicolumn{7}{|l|}{ Sex: ${ }^{\star}$} \\
\hline Total & 99 & 95 & 21 & 49 & 344 & 329 \\
\hline Men & $57(57.6)$ & $59(62.1)$ & $14(66.7)$ & $23(46.9)$ & $120(34.9)$ & $123(37.4)$ \\
\hline Women & $42(42.4)$ & $36(37.9)$ & $7(33.3)$ & $26(53.1)$ & $224(65.1)$ & $206(62.6)$ \\
\hline \multicolumn{7}{|l|}{ Age: $\neq$} \\
\hline Mean (SD) & $76.8(6.7)$ & $76.5(6.5)$ & $78.2(6.1)$ & $77.9(6.5)$ & $79.3(6.9)$ & $78.5(7.0)$ \\
\hline \multicolumn{7}{|l|}{ Education: } \\
\hline$<$ High school & $18(18.2)$ & $13(13.7)$ & $9(42.9)$ & $8(16.3)$ & $87(25.3)$ & $54(16.4)$ \\
\hline High school & $38(38.4)$ & $19(20.0)$ & $5(23.8)$ & $13(26.6)$ & $112(32.6)$ & $91(27.7)$ \\
\hline$>$ High school & $43(43.4)$ & $63(66.3)$ & $7(33.3)$ & $28(57.1)$ & $145(42.2)$ & $184(55.9)$ \\
\hline \multicolumn{7}{|l|}{ Ethnicity } \\
\hline White & $89(89.9)$ & $92(96.8)$ & $13(61.9)$ & $46(93.9)$ & $302(87.8)$ & $315(95.7)$ \\
\hline Black & $7(7.1)$ & $3(3.2)$ & $4(19.0)$ & $2(4.1)$ & $30(8.7)$ & $7(2.1)$ \\
\hline Asian & $3(3.0)$ & $0(0.0)$ & $3(14.3)$ & $0(0.0)$ & $9(2.6)$ & $3(0.9)$ \\
\hline Other & $0(0.0)$ & $0(0.0)$ & $1(4.8)$ & $1(2.0)$ & $3(0.9)$ & $4(1.2)$ \\
\hline \multicolumn{7}{|c|}{ Mini mental state examination score: $\int$} \\
\hline Mean (SD) & $20.9(5.0)$ & $28.4(1.5)$ & $19.3(7.0)$ & $28.4(1.4)$ & $20.7(6.8)$ & $28.2(1.6)$ \\
\hline
\end{tabular}


Table 3 Proportions of cases and controls reported by the industrial hygienist to ever having been exposed occupationally to aluminium and solvents

\begin{tabular}{|c|c|c|c|c|c|c|}
\hline & \multicolumn{2}{|c|}{$\begin{array}{l}\text { Cases }^{*} \text { (spouse } \\
\text { information) }\end{array}$} & \multicolumn{2}{|c|}{$\begin{array}{l}\text { Controls }^{\dagger} \text { (spouse } \\
\text { information) }\end{array}$} & \multicolumn{2}{|c|}{$\begin{array}{l}\text { Controls }^{ \pm} \text {(direct } \\
\text { information) }\end{array}$} \\
\hline & $n$ & $\%$ & $n$ & $\%$ & $n$ & $\%$ \\
\hline Aluminium & 17 & 19.1 & 12 & 13.5 & 15 & 17.4 \\
\hline Solvents & 35 & 39.3 & 26 & 29.2 & 23 & 26.7 \\
\hline
\end{tabular}

${ }^{\star}$ Of a total of 89 case spouses reporting on cases.

tOf a total of 89 control spouses reporting on controls.

$\ddagger$ Of a total of 86 controls reporting for themselves.

Table 4 Odds ratios (95\% CIs) for occupational exposure to solvents

\begin{tabular}{|c|c|c|c|c|c|}
\hline & & \multicolumn{2}{|c|}{ Unadjusted } & \multicolumn{2}{|c|}{ Adjusted ${ }^{\star}$} \\
\hline & & $O R$ & $(95 \% C I)$ & $O R$ & $(95 \% C I)$ \\
\hline Model 1 & Ever/never & 1.90 & (0.88 to 4.09$)$ & 1.77 & (0.81 to 3.90$)$ \\
\hline Model 2 & $\begin{array}{l}\text { Duration of exposure (y): } \\
\text { Low : } 1-17 \text { (median) } \\
\text { High: } \geqslant 18 \\
\text { p Value (trend) }\end{array}$ & $\begin{array}{l}1.24 \\
2.99 \\
0.02\end{array}$ & $\begin{array}{l}(0.50 \text { to } 3.07) \\
(1.15 \text { to } 7.77)\end{array}$ & $\begin{array}{l}1.10 \\
2.62 \\
0.03\end{array}$ & $\begin{array}{l}\text { (0.43 to } 2.82) \\
\text { (1.07 to } 7.43)\end{array}$ \\
\hline Model 3 & $\begin{array}{l}\text { Intensity: } \\
\text { Low } \\
\text { Moderate-high } \\
\text { p Value (trend) }\end{array}$ & $\begin{array}{l}2.47 \\
1.56 \\
0.29\end{array}$ & $\begin{array}{l}(0.95 \text { to } 6.42) \\
(0.66 \text { to } 3.70)\end{array}$ & $\begin{array}{l}2.46 \\
1.37 \\
0.46\end{array}$ & $\begin{array}{l}(0.92 \text { to } 6.57) \\
(0.60 \text { to } 3.36)\end{array}$ \\
\hline Model 4 & $\begin{array}{l}\text { Intensity } \times \text { duration: } \\
\text { Low : } 1-30 \text { (median) } \\
\text { High: } \geqslant 31 \\
\text { p Value (trend) }\end{array}$ & $\begin{array}{l}0.2 \\
1.73 \\
2.11 \\
0.23\end{array}$ & $\begin{array}{l}(0.71 \text { to } 4.21) \\
\text { (0.84 to } 5.32)\end{array}$ & $\begin{array}{l}1.57 \\
2.00 \\
0.13\end{array}$ & $\begin{array}{l}(0.62 \text { to } 3.96) \\
(0.79 \text { to } 5.10)\end{array}$ \\
\hline Model 5 & $\begin{array}{l}\text { Age at half cumulative exp } \\
\text { Low }: 1-33 \text { (median) } \\
\text { High: } \geqslant 34 \\
\text { p Value (trend) }\end{array}$ & ure: & & $\begin{array}{l}1.20 \\
2.67 \\
0.12\end{array}$ & $\begin{array}{l}(0.48 \text { to } 3.00) \\
(1.03 \text { to } 6.94)\end{array}$ \\
\hline
\end{tabular}

${ }^{\star}$ Adjusted for age and education.

age and education, changed little (age $\leqslant 33$, OR $1.4,95 \%$ CI 0.5 to 3.7 ; age $>33$ : OR $2.5,95 \%$ CI 0.8 to 7.6 ) and the OR for cumulative exposure was 0.997 (95\% CI 0.987 to 1.008 ), suggesting that it was not the amount of exposure that was important, but rather whether half of the cumulative exposure occurred later or earlier in life.

\section{ALUMINIUM}

There were 23 discordant pairs that formed the crude OR for aluminium. Table 5 shows unadjusted and adjusted ORs (95\% CIs) for the dichotomous exposures and for dose-response measures of occupational exposures to aluminium. The variables for age and education were not significant in any of the models; age was left in the model to adjust for any residual confounding, and education was added be-

Table 5 Odds ratios (95\% CIs) for occupational exposure to aluminium

\begin{tabular}{|c|c|c|c|c|c|}
\hline & & \multicolumn{2}{|c|}{ Unadjusted } & \multicolumn{2}{|c|}{ Adjusted $^{\star}$} \\
\hline & & $O R$ & $(95 \% C I)$ & OR & $(95 \% C I)$ \\
\hline Model 1 & Ever/never & 1.56 & (0.67 to 3.59$)$ & 1.46 & (0.62 to 3.42$)$ \\
\hline Model 2 & $\begin{array}{l}\text { Duration of exposure (y): } \\
\text { Low : } 1-5 \text { (median) } \\
\text { High: } \geqslant 6 \\
\text { p Value (trend) }\end{array}$ & $\begin{array}{l}0.95 \\
2.19 \\
0.18\end{array}$ & $\begin{array}{l}(0.28 \text { to } 3.20) \\
(0.75 \text { to } 6.36)\end{array}$ & $\begin{array}{l}0.89 \\
2.04 \\
0.24\end{array}$ & $\begin{array}{l}(0.26 \text { to } 3.09) \\
(0.69 \text { to } 5.98)\end{array}$ \\
\hline Model 3 & $\begin{array}{l}\text { Intensity: } \\
\text { Low } \\
\text { Moderate-high } \\
\text { p Value (trend) }\end{array}$ & $\begin{array}{l}4.82 \\
0.79 \\
0.80\end{array}$ & $\begin{array}{l}(1.05 \text { to } 22.16) \\
(0.27 \text { to } 2.27)\end{array}$ & $\begin{array}{l}4.52 \\
0.76 \\
0.92\end{array}$ & $\begin{array}{l}(0.97 \text { to } 21.11) \\
(0.26 \text { to } 2.20)\end{array}$ \\
\hline Model 4 & $\begin{array}{l}\text { Intensity } \times \text { duration: } \\
\text { Low } 1-25 \text { (median) } \\
\text { High: } \geqslant 26 \\
\text { p Value (trend) }\end{array}$ & $\begin{array}{l}1.59 \\
1.52 \\
0.58\end{array}$ & $\begin{array}{l}(0.56 \text { to } 4.53) \\
(0.47 \text { to } 4.86)\end{array}$ & $\begin{array}{l}1.53 \\
1.37 \\
0.35\end{array}$ & $\begin{array}{l}(0.52 \text { to } 4.46) \\
(0.42 \text { to } 4.48)\end{array}$ \\
\hline Model 5 & $\begin{array}{l}\text { Age at half cumulative exp } \\
\text { Low : } 1-34 \text { (median) } \\
\text { High: } \geqslant 35 \\
\text { p Value(trend) }\end{array}$ & ure: & & $\begin{array}{l}1.28 \\
1.69 \\
0.35\end{array}$ & $\begin{array}{l}(0.40 \text { to } 4.11) \\
(0.50 \text { to } 5.83)\end{array}$ \\
\hline
\end{tabular}

${ }^{\star}$ Adjusted for age and education. cause it was initially considered to be an important confounder that should be rigorously controlled.

Although the unadjusted and adjusted ORs were slightly greater than 1.0, neither was significant (table 5). For duration of exposure, the OR also increased between exposure levels (low and high) but the OR for the higher exposure level was only 2.0, and the trend was not significant between exposure levels $(p=0.24)$. Adjusted analyses of maximum intensity of aluminium exposure (model 3) showed that the risk for $\mathrm{AD}$ decreased as the intensity of exposure increased, but none of the ORs was significant and no trend was evident. When the data were analysed combining intensity of exposure and duration of exposure in years across all jobs, there was no dose-response effect (model 4).

Age at which half the cumulative exposure was achieved was not significant (for the continuous variable of age at half cumulative exposure, adjusted for age and education, OR $1.01,95 \%$ CI 0.99 to 1.03 ). Adjusted analyses dichotomising this continuous variable into less than the median ( 35 years old) and the median to the highest age at half cumulative exposure (65 years old) (model 5) showed a slight increase in the ORs, but this trend was not significant $(\mathrm{p}=0.35)$.

Lastly, models including an interaction term for exposure by sex also did not add significantly to the fit of the models, although few women were exposed (one of 12 controls as rated by the industrial hygienist). Separate analyses showed that alcohol consumption was neither a confounder nor an effect modifier of the association between exposure to solvents or aluminium and $\mathrm{AD}$.

\section{Discussion}

SOLVENTS

In this matched case-control study of 89 probable cases of $\mathrm{AD}$ and 89 controls, we found a non-significant association with occupational exposures to solvents as rated by an industrial hygienist. A significantly higher risk was apparent with increased exposure. However, when the intensity level of each exposed job rated by the industrial hygienist was multiplied by the number of years on the job (a measure that assesses total body burden of exposure in a more biologically valid manner), ${ }^{39}$ the increase in risk with increasing dose was no longer significant. Moreover, results examining the risk of $\mathrm{AD}$, given each exposed person's maximum intensity of solvent exposure alone, showed an inverse relation between risk and exposure, and analyses of the age at which half the cumulative exposure occurred showed that although older age predicted increased risk, this was independent of the total amount of exposure.

These results suggest that either: $(a)$ solvent exposure increases the risk of $\mathrm{AD}$ in a manner that is associated only with the number of years of exposure, rather than the maximum intensity or cumulative amount of exposure, which seems unlikely, or $(b)$ the association between $\mathrm{AD}$ and solvents may be due not to the biological effects of these compounds, but pos- 
sibly to other characteristics of jobs that involve solvent exposure. One characteristic of such jobs is their lower occupational status. Job selection is determined by many factors, including education, intelligence, personality, health practices, and parents' occupation. ${ }^{13} 40-42$ Lower education, lower lifetime occupational attainment, and lower income are reported to be risk factors for $\mathrm{AD}{ }^{43-46}$ It has been suggested that premorbid intelligence may underlie this association. ${ }^{10}{ }^{47}$ One possible explanation of the findings is that people with lower premorbid intelligence may remain in occupations with higher exposure to solvents for longer periods than those with greater intelligence, who are able to advance to occupations with less risk of exposure. Therefore, the association between the number of years of exposure and $\mathrm{AD}$ may be confounded with the person's proclivity to remain longer in manual jobs likely to have exposure to solvents. Similarly, those who remain longer in jobs exposed to solvents would experience half their lifetime exposure later in life than those who leave such jobs for those where exposure is less intense or less likely. In our data, lower education was associated with solvent exposure among both case and control spouses $(p=0.03$ and $p=0.01$, respectively).

Alternatively, the association between solvent exposure and $\mathrm{AD}$ may reflect a biological change attributable to low level occupational insults on cerebral function. The possibility that cumulative exposure to solvents may increase the susceptibility to $\mathrm{AD}$ has not been ruled out, ${ }^{48}$ but needs to be considered with prospective occupational study designs that adequately control for alcohol consumption, premorbid intelligence, and socioeconomic status of the subject and that of the family of origin. Preclinical deficits in neuropsychological performance due to exposure to solvents have been reported, controlling for premorbid cognitive ability with a multiple choice vocabulary test, ${ }^{49}{ }^{50}$ the national adult reading test, ${ }^{51}$ and the Wechsler adult intelligence scale..$^{5-54}$ The observed pattern of deficits in performance may be explained by lesions in the frontal or limbic systems of the brain..$^{53}$

Studies of the relation between occupational exposure to solvents and dementia have shown both positive ${ }^{1314}$ and negative results. ${ }^{15-17}$ Most of these studies focused on samples from subjects who were not of sufficient age to be at risk for AD. Early case-control studies of AD found no association with occupational exposures to solvents ${ }^{18-20}$ and a pooled re-analysis of raw data from these studies showed no association, despite improved statistical power. ${ }^{21}$ More recently, the Canadian study on health and aging $^{22}$ found no association between $\mathrm{AD}$ and occupational exposures to solvents (OR 0.8, $95 \%$ CI 0.4 to 1.5). All of these studies assessed exposures by asking case and control informants whether the subject had been exposed to solvents in any job or in the job held for the longest period during the subject's lifetime. The most recent case-control study ${ }^{23}$ used a methodology very similar to the one used here. In that study, Gun et $a l^{23}$ measured occupational exposures from a job exposure matrix and a panel of three industrial hygienists who were blinded to case-control status. The industrial hygienists' rated exposure to solvents from a complete occupational history obtained from case and control informants. None of the estimated risks for exposure to solvents were significantly increased in their study.

The current study used a subsample of 344 probable cases of $\mathrm{AD}$ and 329 controls from the parent study. ${ }^{12}$ In that study, which used proxies of all types for cases and controls, the adjusted OR between exposure to solvents and $\mathrm{AD}$ was 2.3 (95\% CI 1.1 to 4.7$)$, among men it was 6.0 (95\% CI 2.1 to 17.3 ), and among women 0.7 (95\% CI 0.2 to 2.1$)$. It is possible that differential recall bias (controls underreporting) may have resulted in the increased ORs for men in that study.

No significant modification of effect by sex was found in the current study. For men the OR was 2.0, and for women 1.0. These ORs did not differ significantly from one another. It is likely, however, that we did not have sufficient statistical power to detect a true difference between men and women in this study, as few women were exposed.

In the present study, $26 \%-29 \%$ of the controls were rated as exposed by the industrial hygienist. In the study of Gun et al, ${ }^{23}$ a similar proportion of the controls were reported to have been exposed to any hydrocarbon, also based on the opinions of industrial hygienists. In other studies that assessed exposure from informants from the principal lifetime occupation, the controls' rate of exposure to solvents has been lower: $24.1 \%$ in the study of Shalat et $a \bar{P}^{5} ; 20.9 \%$ in the pooled analysis of raw data from three case-control studies ${ }^{21} ; 16.1 \%$ in the $\mathrm{CHSA}^{22} ; 14 \%$ in the parent study ${ }^{12}$; and $7 \%$ in the study of O'Flynn et al. ${ }^{16}$ Therefore, a more careful assessment of exposure performed for each job held throughout the subjects' careers by industrial hygienists instead of lay informants may lead to a more accurate reflection of occupational exposure to solvents in the population at large. Also, the use of industrial hygienists to assess exposure has been recommended over that of proxies. ${ }^{33}$ It would be preferable if possible to use a team of industrial hygienists that rate exposures independently so that reliability of exposure can be assessed; however, this was not possible in the current study.

\section{ALUMINIUM}

For occupational exposures to aluminium, a non-significant association with Alzheimer's disease was found, and dose-response analyses were not significant for duration of exposure in years, intensity of exposure, and age at which half the cumulative lifetime exposure was achieved. The current study provides little evidence to support the role of exposure to aluminium as a risk factor for $\mathrm{AD}$.

Previous studies of the association between aluminium and $\mathrm{AD}$ have led to inconsistent findings. Due to the uniform exposure of human populations to aluminium in food, air, water and soil, epidemiological studies of this 
association are difficult to conduct. Only two occupational studies of the relation between aluminium and cognition exist in the scientific literature; one of workers in a primary aluminium smelter ${ }^{56}$ and another of miners in North Ontario, Canada ${ }^{57}$ exposed daily to an aluminium powder as a prophylaxis against silicosis. Echeverria et $a l^{50}$ found small, nonspecific dose-response associations for various neurological symptoms including memory, headache, dizziness, numbness, and incoordination, but no common diagnosis could be assigned to affected workers. Rifat et $a \bar{l}^{77}$ compared miners exposed to "McIntyre powder" with a group of unexposed miners. An OR of 2.6 was reported for impairment on at least one of three cognitive tests, with a dose-response effect associated with increasing duration of exposure.

Another source of regular exposure to aluminium is through drinking water (for reviews, see Doll ${ }^{58}$ and Graves and Kukull ${ }^{6}$ ). Studies of the aluminium concentration in drinking water and $\mathrm{AD}$ have generally shown small positive effects, some with dose-response associations. Most of the drinking water study designs were ecological and subject to differences in exposure ascertainment, diagnostic referral, and access to medical facilities. One case-control study reported a positive association between the use of antacids (although not specifically antacids containing aluminium) and $\mathrm{AD}$, as well as an increased OR and doseresponse effect associated with the use of antiperspirants containing aluminium. ${ }^{59}$ The $\mathrm{Ca}$ nadian study on health and aging also found an increased risk of $\mathrm{AD}$ associated with the use of antiperspirants (OR 4.8, 95\% CI 1.7 to 13.9), but only among their sample residing in nursing homes. ${ }^{22}$

To our knowledge, this is the second study of occupational exposures and $\mathrm{AD}$ that collected lifetime occupational histories and used the expertise of industrial hygienists to blindly rate exposures. Because the role of occupation cannot be distinguished from the possible role of exposure to neurotoxins at work with a case-control approach, future studies should be done among exposed and unexposed occupational cohorts who are followed up over time for the development of incident Alzheimer's disease and for whom pre-exposure or premorbid measurement of intelligence quotient can be obtained, perhaps through the acquisition of academic records or standardised test results.

This study was supported by NIA R29 AG08921. We thank Shirley Haley, Sheila O’Connell, and Beverly Strain.

1 Hardy J. Alzheimer's disease: clinical molecular genetics. Clin Geriatr Med 1994;10:239-47.

2 Strittmatter WJ, Saunders AM, Schmechel D, et al. Apolipoprotein E: high-avidity binding to $\beta$-amyloid and increased frequency of type 4 allele in late-onset familial Alzheimer disease. Proc Natl Acad Sci 1993;90:1977-81.

3 Corder EH, Saunders AM, Strittmatter WJ, et al. Gene dose of apolipoprotein E type 3 allele and the risk of Alzheimer's disease in late-onset families. Science 1993;261:921-3.

4 Selkoe DJ. Deciphering Alzheimer's disease: molecular genetics and cell biology yield major clues. The fournal of NIH Research 1995;7:57-64.

5 van Duijn CM, Clayton D, Chandra V, et al. Familial aggregation of Alzheimer's disease and related disorders: a collaborative re-analysis of case-control studies. Int $\mathcal{f}$ Epidemiol 1991;20:S13-20.

6 Graves AB, Kukull WA. The epidemiology of dementia. In Morris JC, ed. Handbook of dementing illnesses. New York: Marcel Dekker, 1994:23-69.

7 McGeer PL, Schulzer M, McGeer EG. Arthritis and anti-inflammatory agents as possible protective factors for Alzheimer's disease: a review of 17 epidemiologic studies. Neurology 1996;47:425-32.

8 van Duijn CM, Havekes LM, Broeckhoven C, et al. Apolipoprotein E genotype and association between smoking and early onset Alzheimer's disease. BMF 1995;310: ing and

9 Tang M, Jacobs D, Stern Y, et al. Effect of oestrogen during menopause on risk and age at onset of Alzheimer's disease. menopause on risk and age

10 Mortimer JA, Graves AB. Education and other socioeconomic determinants of dementia and Alzheimer's disease. Neurology 1994;43(suppl 4):S39-44.

11 Arlien-Søborg P. Solvent neurotoxicity. Boca Raton, FL: CRC Press, 1992.

12 Kukull WA, Larson EB, Bowen JD, et al. Solvent exposure as a risk factor for Alzheimer's disease: a case-control study. Am 7 Epidemiol 1995;141:1059-71.

13 Mikkelsen S. A cohort study of disability pension and death among painters with special regard to disabling presenile dementia as an occupational disease. Scand $\mathcal{f}$ Soc Med 1980;16:34-43.

14 Axelson O, Hane M, Hogstedt C. A case-reference study of neuropsychiatric disorders among workers exposed to solneuropsychiatric disorders among workers expose

15 Cherry NM, Labrèche FP, McDonald JC. Organic brain damage and occupational solvent exposure. Br f Ind Med 1992;49:776-81.

16 O'Flynn RR, Monkman SM, Waldron HA. Organic solvents and presenile dementia: a case-referent study using death certificates. Br f Ind Med 1987;44:259-62.

17 Labrèche FP, Cherry NM, McDonald JC. Psychiatric disorders and occupational exposure to solvents. $\mathrm{Br} F$ Ind $\mathrm{Med}$ 1992;49:820-5

18 Heyman A, Wilkinson WE, Stafford JA, et al. Alzheimer's disease: a study of the epidemiological aspects. Ann Neurol 1984;15:335-41.

19 French LR, Schuman LM, Mortimer JA, et al. A case-control study of dementia of the Alzheimer type. $A m \mathcal{F}$ Epidemiol 1985;121:414-21.

20 Shalat SL, Seltzer B, Pidcock C, et al. Risk factors for Alzheimer's disease: a case-control study. Neurology 1987;37: 1630-3.

21 Graves AB, van Duijn CM, Chandra V, et al. Occupationa exposures to solvents and lead as risk factors for Alzheimer's disease: a collaborative re-analysis of case-control studies. Int $\mathcal{F}$ Epidemiol 1991;20(suppl 2):S58-61.

22 The Canadian study of health and aging: risk factors for Alzheimer's disease in Canada. Neurology 1994;44:2073-

23 Gun RT, Korten AE, Jorm AF, et al. Occupational risk factors for Alzheimer's disease: a case-control study. Alzheimer tors for Alzheimer's disease: a case

24 Klatzo I, Wisniewski HM, Streicher E. Experimental production of neurofibrillary degeneration: I. Light microscopic observations. I Neuropathol Exp Neurol 1965;24 187-99.

25 Wisniewski HM, Sturman JA, Shek JW. Aluminium chloride induced neurofibrillary changes in the developing rabbit: a chronic animal model. Ann Neurol 1980;8:479-90.

26 Perl DP, Brody AR. Alzheimer's disease: $x$ ray spectrographic evidence of aluminum accumulation in neurofibrillary-bearing neurons. Science 1980;208;297-9.

27 Landsberg JP, McDonald B, Watt F. Absence of aluminum in neuritic plaque cores in Alzheimer's disease. Nature in neuritic plaque

28 Larson EB, Kukull WA, Teri L, et al. University of Washington Alzheimer's disease patient registry 1987-8. Aging 1990;2:404-8.

29 Kukull WA, Hinds TR, Schellenberg GD, et al. Increased platelet membrane fluidity as a diagnostic marker for Alzheimer's disease: a test in population-based cases and controls. Ann Neurol 1992;42:607-14.

30 McKhann G, Drachman D, Folstein M, et al. Clinical diagnosis of Alzheimer's disease: report of the NINCDS/ ADRDA Work Group under the auspices of the Department of Health and Human Services Task Force on Alzheimer's disease. Neurology 1984;34:939-44.

31 Folstein MF, Folstein SE, McHugh PR. Mini-mental state: a practical method for grading the cognitive state of a practical method for grading the cognitive state of

32 Hawkins NC, Evans JS. Subjective estimation of toluene exposures: a calibration study of industrial hygienists. Appl Ind Hyg 1989;4:61-8.

33 Stewart PA, Stewart WF. Occupational case-control studies: II. Recommendations for exposure assessment. Am $\mathcal{F}$ Ind Med 1994;26:313-26.

$34 \mathrm{McGuire}$ V, Nelson LM, Koepsell TD, et al. Assessment of occupational exposures in community-based case-contro studies. Ann Rev Public Health 1998; (in press).

35 Belletti I, Troschel L, Pisani P, et al. Retrospective assessment of exposure by experts: the example of formaldehyde, solvents and mineral oils among textile and metal workers. Int f Epidemiol 1993;22:S127-33.

36 Schlesselman JJ. Case-control studies: design, conduct, and analysis. New York: Oxford University Press, 1982:208.

37 Hosmer DW Jr, Lemeshow S. Applied logistic regression. New York: John Wiley, 1989:187-215. 
38 SAS/STAT user's guide, version 6, fourth edition. Cary, NC: SAS Institute, 1990

39 Ford DP, Schwartz BS, Powell G, et al. A quantitative approach to the characterization of cumulative and average solvent exposure in paint manufacturing plants. $\mathrm{Am}$ Ind Hyg Assoc F 1991,52:226-34.

40 McCall RB. Childhood IQs as predictors of adult education and occupational status. Science 1977;197:482-3.

41 Matarozzo JD. Wechsler's measurement and appraisal of adult intelligence. New York: Oxford University Press, 1972.

42 Borgatta E, Borgatta M. Encyclopedia of sociology. New York: MacMillan, 1982

43 Stern Y, Gurland B, Tatemichi T, et al. Influence of education and occupation on the incidence of Alzheimer's tion and occupation on the incide. $7 A M A 1994 ; 271: 1004-10$.

44 Bonaiuto S, Rocca WA, Lippi A, et al. Education and occupation as risk factors for dementia: a population-based pation as risk factors for dementia: a population-basc

$45 \mathrm{Li} \mathrm{G}$, Shen YC, Chen CH, et al. A three-year follow-up study of age-related dementia in an urban area of Beijing. Acta Psychiatr Scand 1991;83:99-104.

46 Evans DA, Hebert LE, Beckett LA, et al. Low education and other socioeconomic factors as predictors of incident clinically diagnosed Alzheimer's disease in a community population [abstract]. Am F Epidemiol 1992;136:998.

47 Breitner JCS, Welsh KA. Genes and recent developments in the epidemiology of Alzheimer's disease and related dementia. Epidemiol Rev 1995;17:39-47.

48 Bleeker ML. Invited commentary: solvent exposure as a risk factor for Alzheimer's disease: a multiple insult hypothesis. factor for Alzheimer's disease: a mult

49 Lehrl S, Triebig G, Fischer B. Multiple choice vocabulary test MWT as a valid and short test to estimate premorbid intelligence. Acta Neurol Scand 1995;91:335-45.
50 Triebig G, Lehrl S, Welte D, et al. Arbeits medizininische und testpsychologische feld-studie zur akuten und chronischen neurotoxizitat von styrol unter gegen wartigen expositions bedingugen. Stuttgart, Gentma: Kongresband der Gemeinsamen, 1989:93-7.

51 Cherry $\mathrm{N}$, Venables $\mathrm{H}$, Waldron HA. British studies of neurological effects of solvent exposure. Scand $\mathcal{F}$ Work Environ Health 1984;10(suppl 1):10-12.

52 Echeverria D, White RF, Sampaio C. A behavioral evaluation of PCE exposure in patients and drycleaners: a possible relationship between clinical and preclinical effects. F Occup Environ Med 1995;37:667-80.

53 White RF, Proctor SP, Echeverria D, et al. Neurobehavioral effects of acute and chronic mixed solvent exposure in the effects of acute and chronic mixed solvent exposure in the

54 Mutti A, Mazzucchi A, Rustichalli P, et al. Exposure-effect and exposure-response relationships between occupational exposure to styrene and neuropsychological function. $A m \mathcal{F}$ Ind Med 1984,5:275-86.

55 Shalat SL, Seltzer B, Baker EL Jr. Occupational risk factors and Alzheimer's disease: a case-control study. $\mathcal{F} \mathrm{Occup} \mathrm{Med}$ 1988;30:934-6.

56 Echeverria D, Graves AB, Holland J, et al. An investigation of factors influencing the neurologic health of Intalco aluminum workers. Seattle, WA: Battelle Human Affairs Research Centers, 1989. (Final report BHARC-100/89/9044.)

57 Rifat SL, Eastwood MR, McLachlan DRC, et al. Effect of exposure of miners to aluminum powder. Lancet 1990;336: $1162-5$.

58 Doll R. Review: Alzheimer's disease and environmental aluminium. Age Ageing 1993;2:138-53.

59 Graves AB, White E, Koepsell TD, et al. The association between aluminum-containing products and Alzheimer's between aluminum-containing products
disease. f Clin Epidemiol 1990;43:35-44.

\section{Correspondence and editorials}

Occupational and Environmental Medicine welcomes correspondence relating to any of the material appearing in the journal. Results from preliminary or small scale studies may also be published in the correspondence column if this seems appropriate. Letters should be not more than 500 words in length and contain a minimum of references. Tables and figures should be kept to an absolute minimum. Letters are accepted on the understanding that they be subject to editorial revision and shortening.

The journal also publishes editorials which are normally specially commissioned. The Editor welcomes suggestions regarding suitable topics; those wishing to submit an editorial, however, should do so only after discussion with the Editor. 